\title{
THE CONTROL OF ANOTHER PERSON BY OBSCURE SIGNS
}

\author{
BY G. M. STRATTON
}

Unioersity of Californio

I

The experiments here reported ${ }^{1}$ were upon a young man, a Moravian recently come to San Francisco, known publicly as Eugen de Rubini. ${ }^{2}$

An exhibition of his skill was first observed in private, where perhaps a score of guests were present. There, for nearly two hours, under the direction of various of the guests, he performed feats whose general character was that commonly known as muscle reading, but with an interesting variation. For while, during a brief time of 'warming up,' the subject held in his right hand the one end of a watchchain of which the other end was held in the left hand of his guide,-the chain hanging usually very slack between their hands, - yet this chain was soon laid aside, and the procedure then was without even this mediate contact between guide and subject.

His success in finding things well hidden and in taking objects chosen in his absence and placing them in strange positions also decided upon in his absence,-feats commonly performed by contact,-led to the present experiments under conditions more favorable to precise control and appraisal. Thanks are due him for his readiness to submit to tests which must have seemed to him tedious and full of vain repetition.

1 These experiments were planned in conference with Professor Warner Brown and Professor Edward C. Tolman. Dr. Brown, moreover, was present upon all but the last occasion of experimenting; Dr. Tolman was present throughout. The success of the experiments is as much theirs as the writer's, although he only is responsible for the conclusions here presented.

2 For an account of certain of his European exhibitions, see Frans van Erlevoordt: 'Met den telepaat De Rubini,' Het Leoen, Amsterdam, 14, 806 ff., June 24, 1919; Robert Sigerus: 'Der Telepath Eugen de Rubini,' Zentralblatt für Okkultismus, 12, pp. 21 ff. and 74 ff. 
Throughout these occasions a protocol was made from lots cast by the guide in private, of the particular action to which he was silently to urge the subject; and immediately after each trial there was recorded the subject's success or failure. And thus until the completion of the trial the guide was the only person who knew the precise choice of action determined by the lots. In Series $1-4$ the subject was told immediately after each single trial whether he had succeeded or failed. In Series 5-ro, he was told nothing as to the outcome until the end of Series No. I0; while in Series Nos. I I and 12 , he was told at the close of each series. Particular care was taken to avoid positions where any reflection of the guide might be seen by the subject. The guide stood as nearly behind the subject as was possible while still watching the movements of the subject's hand. 'Contact' in the description that follows will mean the use of the slack watchchain in the manner already described.

During Series I 4 , there were present, besides Dr. Brown, Dr. Tolman and the writer, the subject and his impresario or interpreter (for he himself understands and speaks our language but imperfectly) and Mr. Hillis, a graduate student well known to us. In Series 5-12, the same persons were present, except Mr. Hillis.

No. I. Guide, S.; contact: The subject, standing before a table on which stood a brass bowl, was told that he would be mentally urged by the guide to deposit this bowl upon one or the other of two seats, to the left and right, respectively ; ${ }^{1}$ and that the special direction had been determined in each case by lot.

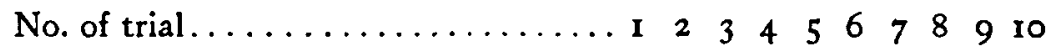
Direction intended by Guide.......R R R L R L R L L R Direction taken by Subject².......R R R L R L $R L \mathrm{R} R$

No. 2. Guide, S.; no contact (except in trials 2 and 3): The subject stood before a table on which was a small vase and, about 15 inches farther from him, two small books, laid side by side. He was told that he might place the vase either upon the right-hand volume or the left, according as the guide mentally urged him.

1 'Left' and 'right,' here and throughout, indicate positions relative to the subject.

Symbols in italic type indicate that the subject's action was correct; i.e., corresponded to the intention of the guide. 
No. of trial

Direction intended by Guide........R L $L$ R R R R L L L Direction taken by Subject.......... $\mathrm{L} R R R \mathrm{~L} \mathrm{~L} R \mathrm{R} L$

No. 3. Guide, S.; mainly with contact (the subject occasionally dropping the chain and proceeding impulsively without it). Ten small volumes of like binding were laid side by side and so spaced that the entire row was about 6 feet long. The subject was told to open, in each trial, but one of the ten volumes, although he might feel and handle, without opening, as many of the volumes as he wished. (The position of the volume is indicated by its number from left to right. They were not numbered for the subject and the guide thought of each by its actual place.)

No. of trial.................... 223456789 10 Volume intended by Guide.............58 $31078428 \quad 2$ Volume opened by Subject............. 7846684583

No. 4. Guide, T.; mainly with contact. Otherwise the conditions and task were as in Series 3.

No. of trial..................... 223456789 10 Volume intended by Guide.............8 2 10 847723844 Volume opened by Subject............6 629984772384

The forty experiments of this first occasion give some indication of his skill, but throw little light upon the conditions which influence his skill.

At our second occasion of experimenting it was felt that if, in some of the series, we were careful to prevent the subject from getting help by hearing, his success would show a marked decline; for on the first occasion no special attention was given to the prevention of sounds; at times the subject and the guide were upon a heavy carpet, and again upon a hard uncarpeted floor; the sound of the feet in the two cases was, of course, noticably different. It was also of interest to discover whether the subject was capable of receiving guidance within very narrow, or only within large, differences. of place.

No. 5. Guide, S.; with contact; on uncarpeted floor: The subject was required to place a metal bowl to $\mathrm{L}$ and $\mathrm{R}$, as in Series No. I. 


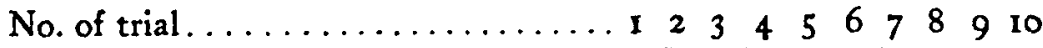
Direction intended by Guide.......R L L R R R L L R L Direction taken by Subject......... L $L L R$ L $R L L R L$

No. 6. Guide, S.; no contact; otherwise the conditions and task were as in Series No. 5 :

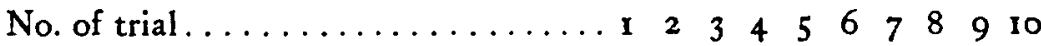
Direction intended by Guide.......R L L L R R L L R L Direction taken by Subject........R R R $L R$ L $\mathrm{R} L \mathrm{~L} R$

No. 7. Guide, S.; no contact: The task, the same as in Series Nos. 5 and 6 . The floor covered with rugs; cotton in ears of subject, and with a heavy coating of vaseline outside of the cotton; heavy doubled woollen muffler over nose and mouth of Guide, who was now in stocking feet:

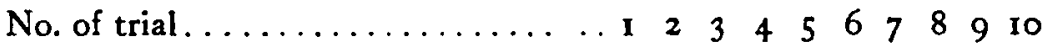
Direction intended by Guide....... L L R R L R L R L L Direction taken by Subject......... $\mathrm{R} R R R R$

No. 8. Guide, S.; no contact. Task and conditions as in No. 7, except that the guide instead of following directly behind the subject all the while, followed him only to the table from which the bowl was taken by the subject; the guide there remained while the subject proceeded to the one or the other of the chairs upon which he placed the bowl.

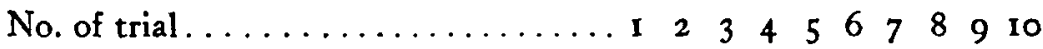
Direction intended by Guide......L R R L R L L L L R Direction taken by Subject........ $R R L R L L R L R$

No. 9. Guide, S.; with contact. Task and conditions as in No. 5 .

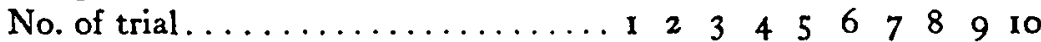
Direction intended by Guide.......L L L R L R R L R L Direction taken by Subject........ $L R R L R R L \mathrm{R} L$

No. 10. Guide, S.; no contact. Task and conditions as in No. 6.

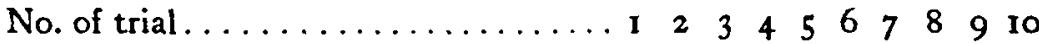
Direction intended by Guide.......R R R L L L L L R $R$ Direction taken by Subject........R R R L L L L R $R R$

No. II. Guide, T.; no contact. Floor uncarpeted; no cotton, etc. in ears of subject; no muffler on guide. Ten small wooden match boxes were placed in a row running left and right, and so 
spaced that the entire row was about 6 feet long. The subject was told to open, in any one trial, but one box, although he might touch and handle as many of them as he chose. (The numbers of the boxes given below indicate their positions from left to right. The boxes, however, were not visibly numbered and the guide usually thought of each by its actual place.)

No. of trial................... I 23456789 10 Box intended by Guide.............. 10 178369542 Box opened by Subject............. 9367465532

No. 12. Guide, T.; no contact. Task and conditions as in No. II, save that the ten match boxes were now placed in two parallel rows, close together, running left and right, 5 boxes in a row. The space between the rows was reduced to about half an inch, so that the ten boxes made a horizontal rectangle about 5 by 10 inches. (The numbers below indicate positions from left to right: $1-5$, in the row farther from the subject; 6-10, in the row nearer him.) No. of trial................... 23456789 10 Box intended by Guide............. 8 10 957716342 Box opened by Subject............. 44532766 I 56 lows:

The data of the experiments, brought together, are as fol-

\begin{tabular}{c|c|c|c|c|c}
\hline \multirow{3}{*}{ No. of Series } & \multirow{3}{*}{$\begin{array}{c}\text { No. of Ex- } \\
\text { periments }\end{array}$} & \multicolumn{2}{c|}{$\begin{array}{c}\text { Outcome to be Expected } \\
\text { by Chance }\end{array}$} & \multicolumn{2}{|c}{ Actual Outcome } \\
\cline { 3 - 6 } & Successes & Failures & Successes & Failures \\
\hline I & 10 & 5 & 5 & 9 & 1 \\
2 & 10 & 5 & 5 & 3 & 7 \\
3 & 10 & 1 & 9 & 4 & 6 \\
4 & 10 & 1 & 9 & 8 & 2 \\
5 & 10 & 5 & 5 & 8 & 2 \\
6 & 10 & 5 & 5 & 4 & 6 \\
7 & 10 & 5 & 5 & 7 & 3 \\
8 & 10 & 5 & 5 & 8 & 2 \\
9 & 10 & 5 & 5 & 7 & 3 \\
10 & 10 & 5 & 5 & 9 & 1 \\
11 & 10 & 1 & 9 & 3 & 7 \\
12 & 10 & 1 & 9 & 1 & 9 \\
\hline Total......... & 120 & 44 & 76 & 71 & 49 \\
\hline
\end{tabular}

The actual successes are thus seen to be about 1.7 times the number which would reasonably be expected were the subject relying upon pure guess-work. 
The indications given by the ratio of successes attained to successes expected by chance are strengthened by the character of the failures. In their size or position these are not such as are most probable by mere coincidence. Such a fact cannot, of course, be detected in those experiments where but one position of erroneous choice is possible, as in Series I, 2, 5-10, where the subject was limited to two lines of action; and if he went wrong, there could be no differences of degree in his mistake. But wherever different grades of failure are possible, where, for example, the error may have any one of nine different positions, and among these are differences of remoteness from the point of success (as in Series $3,4,11$, I2) the subject chose, in 19 of the 24 cases of error, a position which, although wrong, was nevertheless nearer to the right place than is the average of all the wrong positions open to him. The subject evidently received from the guide some kind of cue which distinctly and favorably influenced his choice.

Large Versus Small Differences of Direction.-Separating those series where, other things remaining unchanged, there was in the one group of trials a wide spreading of the ten objects, and in the other a bunching of the ten, the following are the facts:

Outcome Expected by Chance Actual Outcome Successes Failures Successes Failures

$\begin{array}{lcccc}\text { Open order (Series No. I1) ...... I } & 9 & 3 & 7 \\ \text { Closed order (Series No. I2) .... I I } & 9 & \text { I } & 9\end{array}$

The subject appears more successful where the movements open to his choice were widely different in their direction; he was more apt to make a wrong choice among objects close together.

Tentative Choice Versus Final Choice.-The subject repeatedly said that if he could only bring himself to obey his first impulse his success would be greater. The data throw light upon the reliability of this his conviction. For in three series a record was kept-by one of the experimenters other than the guide-of the subject's directions of movement before his final choice. In these series the final choice led to 
success in 12 cases, and to failure in 18 . If he had, in the same series, followed the impulse which was sufficiently clear to be recorded by the observer, his successes would have been only 8 in number and his failures 22 . If in including both successes and failures, we distinguish the failures according as they were more or were less near to success, we find that out of 30 choices the first choice was better than the final choice in 8 cases, and equal to the final choice in 9 cases, and worse than the final choice in 13 cases. The subject's belief that his first impulse was usually better than the one which he finally followed is not supported by the facts. The movement finally approved by him is usually better than that with which he begins.

In seeking for an explanation of his skill, it should be said at once that the subject made no claim to mind-reading in the sense that he could once and for all catch the thought of his guide and, without farther aid, go to the object of which his guide had thought. He needed, he said, to be assisted to the object as would a blind man; there must be by the guide a continual mental correction of his false movements and a corresponding assent and support to the movements that were right; his mind was receptive only to impulsions, and was, so far as possible, inattentive to what the guide might be betraying visibly or by sound; such things disturbed him. Direct observation supported his statement. The experimenters noticed that with his general audience, where they first met him, he several times requested that his guide cease giving certain visible or auditory signs that the subject was going in the right or the wrong direction. And when he was with the experimenters alone, the experiment now following a more reliable method, he gave no appearance of one alert to catch some sign by eye or ear; his eyes were wholly unfurtive; his manner, that of one receptive or dreamy rather than of one who sought to make the most of the externals of his opportunity.

And, farther, the experiments themselves bear out his own account, so far as he denies dependence upon any common or gross sensory signs. 
The muscular and tactual signs, when these were present at all, were of the delicate character made by the very slight differences of tension and contact of a light chain usually quite slack. Yet these slight differences were of marked assistance to the subject. Although the comparison is obviously open to objection, since other differences than the presence or absence of contact enter into the contrasting groups, one may (after eliminating the worst sources of error) roughly say that whereas in the experiments with contact the successes attained are to those expected by chance in the ratio of $2: I$, in those without contact the ratio. is about $3: 2$.

It would also seem reasonable to conclude that, although contact was of assistance to the subject, yet, even without contact, the guide's intention had an effect upon the subject's line of action.

As to the question, what it is that guides him when there is no contact, it would appear that Rubini is not dependent upon hearing. Certain of the experimenters had been confident that he was appreciably helped by the sound of the guide's breathing, and of the lag or alacrity of his footsteps in following, and that with a reduction of these clues there would be a marked reduction in his successes. If anything, there is an increase.

The aids which he might have had from sight were not of a character that would have sufficed for ordinary skill. Throughout the experiments the guide was the only person who knew the position or object which meant success or failure. The other experimenters, when their eyes were directly upon the guide, felt no confidence that they could tell his intention except by his manner after the decision had been made by the subject. It seems improbable that the interpreter, who was present in all but the group of supplementary experiments, was able to interpret beforehand the intention of the guide; it seems still less probable that he was able to signal his interpretation to the subject since he was usually well behind the subject, and farther off from the subject than were the rest of us. It seems more reasonable 
to believe that the subject caught, in the very periphery of his visual field, something in the posture or motion of the guide, which assisted him. There were occasions when the feet and legs of the guide (when the subject looked down), or the guide's whole body (when the subject suddenly changed the direction of his facing) came into the border of the field of his view. Very conflicting shadows of the guide cast within the subject's field may also have been of help. In those experiments in which he was to take up and place a small brass bowl or a small enameled vase, it is possible that obscure reflections of the guide's posture might have helped; but the brass was tarnished and the vase was made of several variant surfaces. And his method of handling them (which commonly was to 'heft' and swing and rapidly twist the object) made it improbable that he got from these any help. Furthermore, in all the series, four in number, and comprising forty trials, in which books or wooden match boxes were used, such reflections, even the most obscure, were impossible. Direct reflections in windows or glass doors, or in the glass of pictures on the walls were carefully considered in arranging the precise location of the experiment. Since, in an occurrence difficult to explain, one must consider even improbable possibilities, such reflections at certain stages of some of the earlier experiments may have existed. But in the series numbered 5 to 12 the conditions were such as to exclude them entirely.

The fact that the subject was unwilling to be blindfolded may be taken as an indication that he depends to some appreciable extent, even though subconsciously, upon visual cues. The experimenters are not inclined to interpret this reluctance as casting doubt on the subject's bona fides. He has been a public exhibitor of his powers in Hungary, Holland and Java; arriving from the Orient, and beginning in San Francisco, he plans to give public exhibitions in America; he is, therefore, justly interested in showing his prowess in its success rather than its failure. His reluctance in regard to blindfolding stands in contrast to his readiness to exclude sounds, an exclusion which proved to be no check upon his 
successes. We may therefore assume that in those experiments where he worked without contact, visual cues of a highly elusive kind were of assistance. Tremors of the floor, faint sounds of the guide's movements-of the feet on the floor, of his arms and clothing (though the subject prescribed a fixed position for these, a prescription which we did not always observe), together with those made by changes in his breathing -these were diminished, but not excluded, by our conditions. In using any or all of these, however, there must have been great sensitiveness and great delicacy of subconscious adjustment to give him the proportion of successes attained. The experimenters each and all assume that these successes depended upon sensory cues of some sort, and not upon an immediate influence of mind upon mind. It is hoped that others will supplement the present manifestly incomplete experiments, and lay bare the nature of these sensory cues.

\section{II}

\section{Supplementary Experiments}

Fortunately it was possible to subject to actual test the conclusions just stated with hesitation. The experiments, as before, were at the home of the writer; and there were present Mr. Rubini, Dr. Tolman, Miss Morrison (our research assistant), and the writer. No interpreter came with him on this occasion; so that the fear that our earlier precautions against the possibility of his signaling might have been insufficient was here set at rest.

In this third group of experiments, Series 13-20, help from shadows and reflections, it is certain, were entirely excluded. A position for the guide and subject was carefully chosen beforehand where with the proper drawing of curtains, all lighting was low and came from the front, and the shadows of the subject were cast well behind him, while those of the guide, who stood behind the subject, were of course still farther to the rear. Pictures under glass that might reflect the guide to the subject were removed. An unglazed piece of pottery was substituted for the brass bowl. Two observers sat well to the rear where their facial expression occasionally 
and when no blinders were upon the subject might at most come into the very border of his vision. These 'blinders' consisted of a black bristol-board cylinder, wrapped completely around the head, cutting off the view, not only at the sides, but above and below, leaving a narrow, more or less circular visual field of about 80 degrees. In certain of the series, as will be noted, there was also used an opaque screen reaching to the floor and extending above the guide's head, surrounding him in front and on two sides and placed near the wall at his rear; and in its front was a narrow rectangular aperture just large enough for his two eyes to watch the subject's movements. There was used too a special helmet-like padding to surround and close over the subject's ears previously tight-plugged with cotton. Experiments beforehand showed that by this means the sound of a ticking clock was reduced to about $I / 150$ of its previous intensity. The guide's mouth and nose were muffled as in Series 7 , and he stood in stocking feet on a heavy rug. The protocols in every case were drawn up privately by the guide, were kept in his inside pocket, and were consulted by him only after the subject with the guide behind him was in position to begin the trial; so that no unintended betrayals might come to the subject from the eyes, posture or movement of the guide. In all the Series 13-20, the subject and guide stood or walked on a well-carpeted floor. No chain or other means of contact was used in any of these series; nor was the subject told the outcome of any of them until the end of Series 20.

No. 13. Guide, S.; no contact. Task as in Series 5-10, to place a small piece of pottery in one of two chosen chairs forward and a few paces to left or right. Guide remained upon the spot where he stood at beginning of each trial; i.e., he did not follow the subject when he moved toward the one or the other of the chairs. No blinders, no screen, no special reduction of sound.

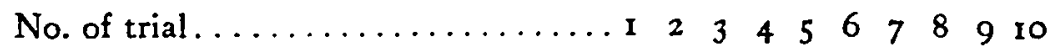
Direction intended by Guide.......L $R$ R L $L R R R R$ Direction taken by Subject........LR R R L L $R$ L L R

No. 14. Guide, S.; no contact. Task and conditions as in No. 13, but with blinders on Subject. 
No. of trial.................. I 233456789 ro Direction intended by Guide......... L L L R R R L R R R Direction taken by Subject.........L R R $R$ L L $L$ L $R R$

No. 15. Guide, S.; no contact. Task and conditions as in No. 14, but with high screen surrounding Guide.

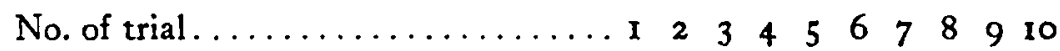
Direction intended by Guide........R L $L$ L $L$ R L R R R L Direction taken by Subject......... L R R $L R$ R L L $R$ R

No. 16. Guide, S.; no contact. Task and conditions as in No. 13; but guide dogging the footsteps of the subject.

No. of trial................. I 22344567899 10 Direction intended by Guide......... R R L L L R R L R L Direction taken by Subject..........L $R L L L L R$ L $L R L$

No. 17. Guide, S.; no contact. Task and conditions as in No. 16, but with blinders on Subject.

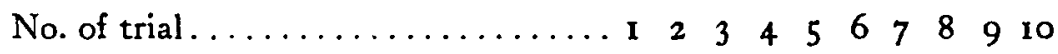
Direction intended by Guide........R R R R L R L L R R Direction taken by Subject..........R $R$ L $R$ R $R L R R$ L

No. I8. Guide, T.; no contact. Task, to open the selected one of ten volumes laid in a row, left to right, on a couch before subject. Blinders on subject. Guide followed close behind subject. No. of trial.................... I 23456789 ro Volume intended by Guide............. 33998656 10 82 Volume opened by Subject............8 7448637106 I

No. 19. Guide, T.; no contact. Task and conditions as in No. 18.

No. of trial.................... 123345678910 Volume intended by Guide............. 597556109874 Volume opened by Subject.............78 8645999862

No. 20. Guide, T.; no contact. Task as in No. 18 , but with blinders, ear-plugs and ear-pads on subject. Guide muffled, in stocking feet, and fully screened.

No. of trial.................... 22345678910 Volume intended by Guide............8 331064467252 Volume opened by Subject............96 684 I 105946 
The following are, in summary, the data of the original and these additional series, which now bring the total number of experiments to 200:

\begin{tabular}{|c|c|c|c|c|c|}
\hline & \multirow{2}{*}{ No. of Exp's } & \multicolumn{2}{|c|}{$\begin{array}{l}\text { Outcome to be } \mathrm{Ex} \text { - } \\
\text { pected by Chance }\end{array}$} & \multicolumn{2}{|c|}{ Actual Outcome } \\
\hline & & Successes & Failures & Successes & Failures \\
\hline 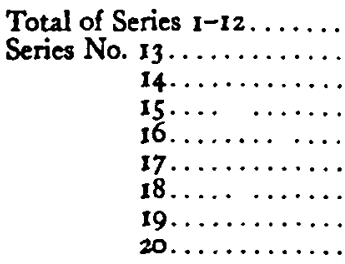 & $\begin{array}{r}120 \\
10 \\
10 \\
10 \\
10 \\
10 \\
10 \\
10 \\
10\end{array}$ & $\begin{array}{r}44 \\
5 \\
5 \\
5 \\
5 \\
5 \\
1 \\
1 \\
1\end{array}$ & $\begin{array}{r}76 \\
5 \\
5 \\
5 \\
5 \\
5 \\
9 \\
9 \\
9\end{array}$ & $\begin{array}{r}71 \\
5 \\
5 \\
3 \\
9 \\
6 \\
3 \\
2 \\
0\end{array}$ & $\begin{array}{r}49 \\
5 \\
5 \\
7 \\
1 \\
4 \\
7 \\
8 \\
10\end{array}$ \\
\hline Total of Series $1-20 \ldots \ldots$ & 200 & 72 & 128 & 104 & 96 \\
\hline
\end{tabular}

Assuming, from the evidence earlier adduced, that auditory impressions are of no great importance in Rubini's work, a fairly reliable index of the value to him of visual cues may be obtained through those experiments where the tactual features were constant.

Taking only these, and comparing the series where there were no extraordinary precautions against visual aids with the series in which such precautions were taken, the following appears in summary:

\begin{tabular}{c|c|c|c|c|c}
\hline Series without Contact & $\begin{array}{c}\text { Outcome to be Ex- } \\
\text { pected by Ch ance }\end{array}$ & \multicolumn{2}{|c|}{ Actual Outcome } \\
\hline $\begin{array}{c}\text { Without special precautions against sight: } \\
\text { Series 6,7,8, 10, 11, 13, 16, (70 trials) }\end{array}$ & 31 & 39 & 45 & 25 \\
$\begin{array}{c}\text { With special precautions against sight: } \\
\text { Series 14, 15, 17, 18, 19, 20, (60 trials).. }\end{array}$ & 18 & 42 & 19 & 41 \\
\hline
\end{tabular}

From this it is clear that while Rubini can with sight and without the help of touch attain about one and a half times as many successes as chance would give, yet when all visual cues from his guide's behavior are excluded, the

1 Series 2 and 12 are omitted because of the peculiar nature of the task; the objects of choice were here bunched, and they offered peculiar difficulties. 
successes at once drop to the number expected by pure chance. ${ }^{1}$

These supplementary experiments, accordingly, fortify the conclusions suggested by those preceding. It was then felt that Rubini received visual aid from signs unintentionally given him by each of the persons who acted as his guidesigns which indicated whether he was approaching or was going away from the right object. These signs were exceedingly obscure, rarely evident to the experimenters watching the guide; and under the conditions of our latest experiments these signs could not have been given by movements of the shadow of the guide cast forward into the visual field of the subject. The hints seem rather to have come from fleeting glimpses of the guide's changes of place and posture caught in the very margin of vision and perhaps without any conscious intention by the subject to notice or use them. Yet upon these, when touch was excluded, his truly remarkable power seems to depend.

1 Although the number of the failures is nearly what we should expect by guessing, yet when we consider their individual character, they are not what would most probably arise by chance. Confining our attention to the 25 failures in Series 18-20 (where there is the possibility of failures of different value) there are 7 which are farther removed from the correct position than is the average of all the possible choices; while 18 are nearer to success than is this average.

There remains accordingly what some might regard as a 'trace' of evidence that the guide, even with the precautions taken, influenced the subject. Still more careful and numerous experiments would be needed to determine what importance, if any, this 'trace' might bave. It is perhaps significant that in Series 20 , where both sight and hearing were limited more than in any other series, there were no successes, and the 10 failures have an average value (namely, 2.9 removes from success) but jittle less than the average value of all possible positions of choice (namely, 3.r removes from success). 